\title{
Wall Materials on the Base of Burned Rocks
}

\author{
Irina G. Endzhievskaya*, Nina G. Vasilovsky, \\ Galina P. Baranova and Ivan S. Voroshilov \\ Siberian Federal University \\ 79 Svobodny, Krasnoyarsk, 660041, Russia
}

Received 20.01.2016, received in revised form 04.02.2016, accepted 23.04.2016

The possibility of obtaining effective wall building materials on the basis of burut rocks of the Krasnoyarsk Territory is shown. The results of studies of basic operational properties of the materials developed are given. The technological methods of making bezobzhigovyh wall materials on the basis of burnt rocks are considered it is found that the products on the basis of burnt rocks are comparable with compression strength of ceramic bricks (GOST 530-2012), but have a significantly higher flexural strength than the ceramic bricks of this mark. Issues of overcoming the heterogeneity of the composition and structure of burned rocks are reflected. The analysis of the properties of wall materials, depending on the production methods is presented.

Keywords: burned rocks, nonfired vibration technology, chemically bonded wall material, dry pressing.

Citation: Endzhievskaya I.G., Vasilovsky N.G., Baranova G.P., Voroshilov I.S. Wall materials on the base of burned rocks, J. Sib. Fed. Univ. Eng. technol., 2016, 9(4), 563-571. DOI: 10.17516/1999-494X-2016-9-4-563-571.

\section{Стеновые материалы}

на основе горелых пород

\section{И.Г. Енджиевская, Н.Г. Василовская, Г.П. Баранова, И.С. Ворошилов Сибирский федеральный университет Россия, 660041, Красноярск, пр. Свободный, 79}

\begin{abstract}
Показана возможность получения эффективных безобжиговых стеновых строительных материалов на основе горелых пород месторождений Красноярского края. Приведень результаты исследований основных эксплуатационных свойств разработанных материалов. Рассмотрены технологические способы изготовления безобжиговых стеновых материалов на основе горелых пород. Установлено, что изделия на основе горелых пород сопоставимы по прочности при сжатии с керамическим кирпичом (ГОСТ 530-2012), но имеют значительно более высокую прочность при изгибе, чем у керамического кирпича данной марки. Отражень
\end{abstract}

(C) Siberian Federal University. All rights reserved

* Corresponding author E-mail address: icaend@mail.ru 
вопросы преодоления неоднородности состава и строения горелых пород (глиежей). Дан анализ свойств безобжиговых стеновых материалов в зависимости от методов производства.

Ключевые слова: горелая порода, глиеж, вибрационная технология, безобжиговый стеновой материал, полусухое прессование.

\section{Введение}

В связи с сохранением высоких темпов строительства жилья, объектов соцкультбыта, здравоохранения, роста индивидуального строительства потребность в стеновых материалах возрастает. В настоящее время более 60 \% всего объема производимых строительных материалов приходится на кирпич.

Востребованность указанного материала на рынке строительных изделий объясняется его несомненными преимуществами: накапливая тепловую энергию, он медленно и равномерно отдает тепло, сохраняя комфортные условия помещения в зимнее время, и защищает дом от чрезмерного нагревания летом. Кирпичная стена паропроницаема - она «дышит», пропуская влагу (в результате в помещениях поддерживается уровень равновесной влажности) в отличие от многих современных материалов, изготовленных по технологиям, малоизвестным в эксплуатации, зачастую несущим угрозу здоровью и самочувствию людей. Недостатком полнотелого кирпича можно считать относительно высокую плотность и теплопроводность.

Важной задачей в современных условиях выступает увеличение производства эффективных стеновых материалов с использованием имеющихся производственных фондов и с наименьшими затратами энергии на их производство. Для повышения теплофизических свойств стеновых материалов необходимо шире использовать местные пористые горные породы и производственные отходы.

Использование горелых пород (глиежей), являющихся попутным продуктом при добыче угля, для производства местных стеновых строительных материалов экономически целесообразно, так как они сочетают в себе ряд положительных свойств - низкую плотность, необходимую прочность и декоративность. Особенность горелых пород - высокая микропористость.

Горелые породы - естественно обожженные глинистые, песчано-глинистые и песчаные отложения, которые в процессе горения подземных пластов углей превратились в обожженный керамический черепок. Качество природных глиежей довольно разнообразно, хотя они значительно однороднее горелых пород террикоников. Их относят к скальным грунтам осадочного типа, вид - силикатные, подвид - аргиллиты, алевролиты и т.п.

В настоящее время в России слабо внедряются результаты научных разработок в части использования сопутствующих продуктов промышленности в производстве строительных материалов. Первые попытки систематизации исследований горелых пород были сделаны в работах Г.И. Книгиной [1]. В зарубежной научной литературе долгое время также уделялось недостаточно внимания изучению возможностей применения глиежа [2-4]. На сегодняшний день время исследованием возможностей применения горелых пород занимаются в ряде промышленных регионов России [5-11].

Несмотря на проведенные исследования, в настоящее время наиболее часто они используются при устройстве земляного полотна в местах добычи. Горелые породы находят применение в качестве добавки в цементы. Некоторые горелые породы имеют пониженную сред- 
нюю плотность, что позволяет применять их в качестве заполнителей для легких растворов и бетонов. Однако развитая сеть микропор в глиежах и развитая поверхность зерен приводят к повышению водоцементного отношения, перерасходу цемента и, соответственно, к снижению физико-механических характеристик бетона, значительному его водопоглощению.

Цель исследования - получение на основе горелых пород эффективных безобжиговых стеновых строительных материалов методом прессования с высокой прочностью, пониженным водопоглощением, отвечающих нуждам современного строительства.

\section{Материалы и методы}

Возможность использования горелых пород для производства стеновых материалов выдвинула задачу изучения их свойств. Были проведены исследования горелых пород Уярского района, а также Бородинского угольного разреза Красноярского края. В качестве вяжущего использовался цемент М500 Д0 (производства ОАО «Холдинговая компания «Сибирский цемент» г. Красноярск).

Проведены следующие исследования: РФА и химический анализ (на рентгеновском дифрактометре Д8-ADVANCE (фирма Bruker) и рентгенофлуоресцентном спектрометре для анализа элементного состава ARL OPTIM,X, компания «ТермоТехно», Швейцария) различных участков глиежа для использования в производстве стеновых материалов. Определение физико-механических свойств глиежей проводилось по методикам ГОСТ на испытание щебней и песков из горных пород для строительных работ.

\section{Результаты}

Химический анализ горелых пород месторождений Красноярского края приведен в табл. 1.

Оценку прочности природных пористых крупных заполнителей предложено делить на четыре группы [12].

В первую входят методы испытания прочности породы в куске выпиленных из глиежа кубиков (табл. 2).

Этот метод позволяет получить показатели прочности отдельных образцов заполнителя. Однако передача усилий на испытуемый образец происходит в условиях одноосного напряженного состояния и не учитываются остальные свойства глиежа в композиции, которые су-

Таблица 1. Химический анализ горелых пород

\begin{tabular}{|l|l|l|c|c|c|c|c|c|c|c|}
\hline \multirow{2}{*}{$\begin{array}{c}\text { Номер } \\
\text { пп }\end{array}$} & $\begin{array}{l}\text { Наименование } \\
\text { месторождения } \\
\text { горелых пород }\end{array}$ & \multicolumn{7}{|c|}{ Содержание оксидов, масс \% } \\
\cline { 3 - 10 } & $\begin{array}{l}\text { Ирша- } \\
\text { Бородинское } \\
\text { месторождение }\end{array}$ & $52,11-68,3$ & $13,5-19,3$ & $3,2-10,1$ & $2,4-8,4$ & $1,0-2,0$ & - & - & - & $1,3-2,1$ \\
\hline 2 & $\begin{array}{l}\text { Уярское } \\
\text { месторождение } \\
\text { (Туляк-2) }\end{array}$ & 63,95 & 19,71 & 8,0 & 2,61 & 1,58 & 0,05 & 0,30 & 2,81 & 1,02 \\
\hline
\end{tabular}

$$
-565-
$$


щественно влияют на прочность изделий: это состояние поверхности заполнителя, сцепление с цементным раствором, самовакуумирование, физико-химическое взаимодействие с цементным камнем и др.

Вторая группа методов испытания включает сдавливание заполнителей в цилиндре, когда зерна глиежа находятся под воздействием сосредоточенных раскалывающих усилий, передаваемых смежным зернам в точках их контакта. Прочность глиежа находится в пределах 13,2 21,1 кгс/см² что соответствует марке щебня по прочности от П 150 до П 250.

Мелкий заполнитель на основе горелой породы имеет насыпную плотность - 1050 кг/м при гранулометрическом составе, представленном в табл. 3.

Данный гранулометрический состав выбирали исходя из следующих соображений: мелкая фракция необходима для создания качественной поверхности изделия, средние фракции примерно в равных долях. Зерна крупной фракции ('3 мм) взяли в увеличенном количестве, поскольку в процессе прессования они подвергаются частичному разрушению, большей частью поверхностного характера, происходит срезание шероховатостей, выступов. За счет этого увеличивается контактная поверхность между ними.

Кроме того, отрабатывали количество вяжущего в шихте, расход воды затворения и давление прессования в лабораторных условиях. Для этого из рабочих составов изготавливали образцы-цилиндры диаметром 50 и высотой 60 мм, часть которых испытывали после тепловлажностной обработки, а часть - в возрасте 28 суток. Затем изготавливали образцы по форме и размерам кирпича в производственных условиях по технологиям вибрационного и полусухого прессования.

Таблица 2. Определение средней плотности и прочности породы в куске

\begin{tabular}{|c|c|c|c|c|}
\hline \multicolumn{2}{|c|}{ Размеры, см } & \multirow{2}{*}{$\begin{array}{c}\text { Масса образцов, } \\
\text { высушенных до } \\
\text { постоянной массы, г }\end{array}$} & \multirow{2}{*}{$\begin{array}{c}\text { Средняя плотность } \\
\rho_{0}, \Gamma / \mathrm{cm}^{3}\end{array}$} & \multirow{2}{*}{$\begin{array}{c}\text { Предел прочности при } \\
\text { сжатии горной породы, } \\
\text { кгс/см²/MПа }\end{array}$} \\
\hline Диаметр & Высота & & & \\
\hline 4,7 & 4,7 & 146 & 1,79 & $230,68 / 22,62$ \\
\hline 4,8 & 4,8 & 142 & 1,63 & $280,97 / 27,55$ \\
\hline 4,8 & 4,8 & 158 & 1,82 & $221,23 / 21,7$ \\
\hline 4,9 & 4,9 & 162 & 1,75 & $288,74 / 28,32$ \\
\hline 4,6 & 4,6 & 170 & 2,08 & $350,39 / 34,36$ \\
\hline
\end{tabular}

Таблица 3. Гранулометрический состав мелкого заполнителя

\begin{tabular}{|c|c|c|c|}
\hline \multirow{2}{*}{ Номер сита } & \multicolumn{2}{|c|}{ Частный остаток, } & \multirow{2}{*}{ Полный остаток, \% } \\
\cline { 2 - 3 } & $\Gamma$ & 70,5 & 70,5 \\
\hline 1,25 & 704 & 5,4 & 75,9 \\
\hline 0,63 & 54 & 3,6 & 79,5 \\
\hline 0,315 & 36 & 5,0 & 84,5 \\
\hline 0,14 & 50 & 15,6 & 100 \\
\hline дно & 156 & & \\
\hline
\end{tabular}


Вследствие неравномерности обжига и неоднородности химического состава горелых пород показатели механической прочности отдельных их разновидностей могут быть разнообразны даже в пределах одного месторождения. Задача преодоления неоднородности в составе и строении глиежей была решена, с одной стороны, технологически - выбором способа формования стеновых изделий, с другой - модифицированием шихты.

В исследованиях рассматривались две технологии изготовления изделий на основе глиежа вибропрессование и полусухое прессование. Изделия, полученные с использованием данных технологий, отличаются высокими эксплуатационными свойствами и физико-механическими характеристиками: прочностью, низким водопоглощением, морозоустойчивостью, точностью геометрических размеров, что позволяет изготавливать изделия с низким содержанием цемента. В заводских условиях изготавливали изделия в форме кирпича на вибропрессе производства Польши «Henkis» - НК-93 и прессе для полусухого формования A300-3 (рис. 1) с характеристиками: максимальное усилие прессования 300 т, количество кирпичей, производимых за одно прессование - 2 шт., длительность цикла прессования (номинальная) 12 с.

Значения физико-механических характеристик изделий на основе глиежа, изготовленных вибропрессованием и испытанных в возрасте 28 сут, приведены в табл. 4, где состав 1 - шихта, содержащая $9 \%$ цемента, без добавок, состав 2 - то же, с модифицирующей добавкой для полусухого вибропрессования с гидрофобизирующим эффектом Murasan BWA 21, производства ООО «Эм-Си Баухеми».

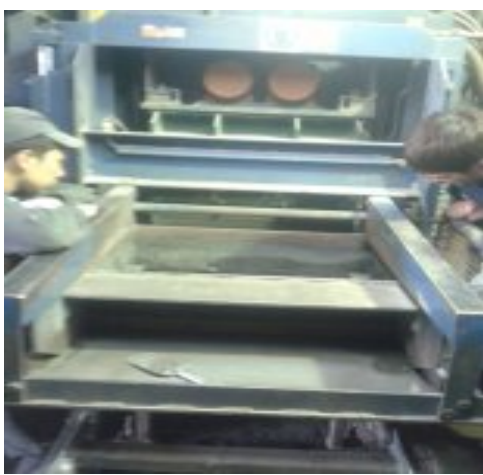

6

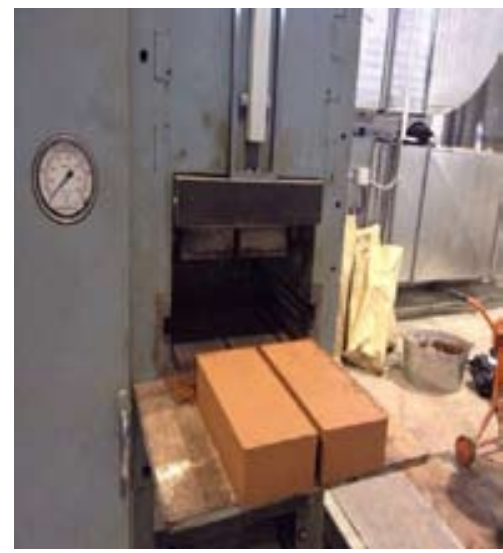

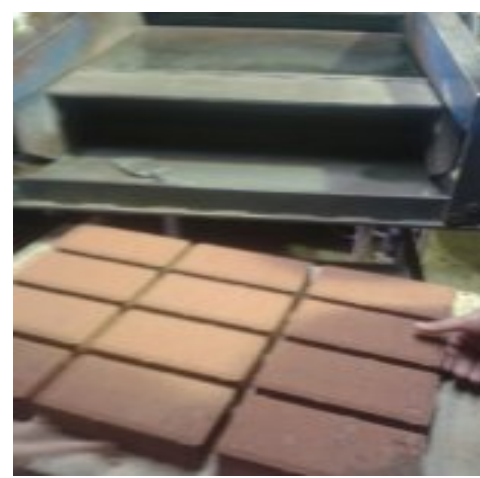

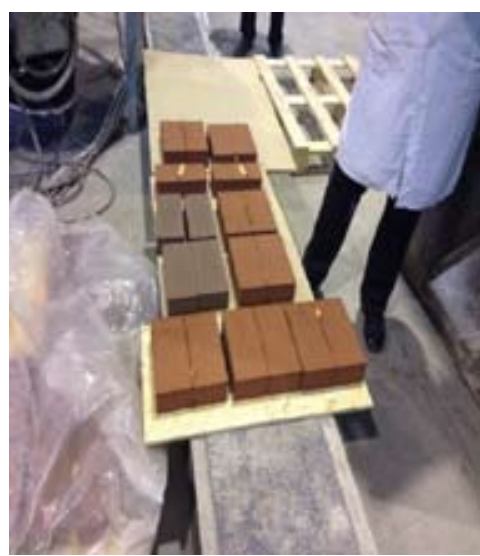

Рис. 1. Выпуск безобжигового кирпича вибро- (а) и полусухим (б) прессованием 
Таблица 4. Физико-механические характеристики образцов, изготовленных методом вибропрессования

\begin{tabular}{|c|c|c|c|c|c|c|}
\hline $\begin{array}{l}\text { Номер } \\
\text { состава }\end{array}$ & $\begin{array}{c}\text { Средняя } \\
\text { плотность после } \\
\text { пропаривания, кг/м }{ }^{3}\end{array}$ & 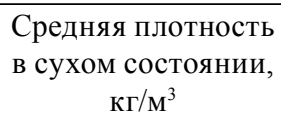 & $R_{\text {изг }}, \mathrm{MПа}$ & $\begin{array}{l}R_{\text {сж, }} \\
\mathrm{M \Pi аa}\end{array}$ & $\begin{array}{c}\text { Водопогло- } \\
\text { щение, \% }\end{array}$ & $\begin{array}{l}\text { Морозостой- } \\
\text { кость, циклы }\end{array}$ \\
\hline 1 & 1690 & 1520 & 0,7 & 8,1 & 24 & 20 \\
\hline 2 & 1650 & 1502 & 0,8 & 10,0 & 17 & 35 \\
\hline
\end{tabular}

Примечание. Смесь уплотнялась методом вибропрессования с заданным давлением 25,0-27,0 МПа.

Таблица 5. Физико-механические свойства безобжигового кирпича на глиеже, изготовленного методом полусухого прессования

\begin{tabular}{|c|c|c|c|c|c|c|c|}
\hline \multirow{2}{*}{$\begin{array}{l}\text { Номер } \\
\text { пп }\end{array}$} & \multirow{2}{*}{ Маркировка } & \multirow{2}{*}{ 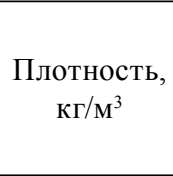 } & \multirow{2}{*}{$\begin{array}{l}\text { Rизг, } \\
\text { МПа }\end{array}$} & \multirow{2}{*}{$\begin{array}{l}\text { Rсж, } \\
\text { МПа }\end{array}$} & \multicolumn{3}{|c|}{$\begin{array}{c}\text { Требования ГОСТ 530-2012 к пределу } \\
\text { прочности керамического кирпича }\end{array}$} \\
\hline & & & & & при сжатии, МПа & $\begin{array}{l}\text { при изгибе, } \\
\text { МПа }\end{array}$ & $\begin{array}{c}\text { марка } \\
\text { изделий }\end{array}$ \\
\hline \multirow[t]{2}{*}{1} & \multirow[t]{2}{*}{ 20Ц+БВА } & \multirow[t]{2}{*}{1753} & \multirow[t]{2}{*}{5,7} & \multirow[t]{2}{*}{23,14} & $\begin{array}{l}\text { Средний 20,0 } \\
\text { Наименьший 17,5 }\end{array}$ & $\begin{array}{l}\text { Средний '3,4 } \\
\text { Наименьший } 1,7\end{array}$ & M200 \\
\hline & & & & & & $\begin{array}{l}\text { Средний '4,4 } \\
\text { Наименьший 4,4 }\end{array}$ & $\begin{array}{c}\text { M400 и } \\
\text { выше }\end{array}$ \\
\hline \multirow[t]{2}{*}{2} & \multirow[t]{2}{*}{ 9Ц+БВА } & \multirow[t]{2}{*}{1630} & \multirow[t]{2}{*}{2,93} & \multirow[t]{2}{*}{13,62} & $\begin{array}{l}\text { Средний } 12,5 \\
\text { Наименьший } \\
10,0\end{array}$ & $\begin{array}{l}\text { Средний 2,5 } \\
\text { Наименьший 1,2 }\end{array}$ & M125 \\
\hline & & & & & & $\begin{array}{l}\text { Средний 2,8 } \\
\text { Наименьший 1,4 }\end{array}$ & M150 \\
\hline
\end{tabular}

Примечание. 1-й состав - $20 \%$ цемента по массе и $0,5 \%$ добавки от массы цемента; 2 -й состав - $9 \%$ цемента по массе и $0,5 \%$ добавки от массы цемента.

Физико-механические характеристики изделий, отформованных методом полусухого прессования, представлены в табл. 5. Подготовленная смесь уплотнялась с заданным давлением 28,0 МПа. Изготовленные образцы-кирпичи размерами 25,0х12,0х6,5 испытаны в возрасте 28 сут.

\section{Обсуждение результатов}

Наиболее эффективна из рассмотренных технологий изготовления изделий технология полусухого прессования, этому способствует низкая прочность горелых пород и их относительно высокая пористость, что приводит к получению безобжигового кирпича плотностью, соответствующей требованиям ГОСТ 530-2012. Изделия из более плотных пород по этой технологии получаются слишком тяжелые, соответственно, с высокой теплопроводностью. Поэтому технология полусухого прессования была принята в качестве основной.

В процессе прессования происходит также удаление газовоздушной фазы и максимальное сближение частиц цемента и глиежа, обнажаются их активные центры. Поэтому интенсифицируются процессы гидратации цемента, уплотняется макро- и микроструктура цементного камня, упрочняется контакт цементного камня с глиежом, препятствующий сдвиговым напряжениям, что определяет эксплуатационные свойства изделий. Это позволяет минимизировать 
расход вяжущего до 9-10 \% и частично преодолеть неоднородность в составе и строении глиежей.

Однако автоматизация процессов, свойственная технологиям жестких бетонных смесей, предъявляет такое требование, как постоянство характеристик шихты независимо от меняющегося содержания воды, а также от гранулометрического состава используемых сырьевых материалов. Показатели прочности бетона-сырца и ранней прочности бетона являются критически важными параметрами процесса производства. Для оптимизации шихты в состав вводили модифицирующую добавку для полусухого прессования MurasanBWA 19 и с гидрофобизирующим эффектом Murasan BWA 21 производства ООО «Эм-Си Баухеми».

Для смесей бездобавочных и с добавкой отмечено следующее: увеличивается диапазон варьирования расхода воды, улучшается внешний вид и качество поверхности изделий, повышается морозостойкость изделий. Морозостойкость изделий, изготовленных методом полусухого прессования, при расходе цемента 12 \% составила 75 циклов (с добавкой Murasan BWA 21) и 50 циклов (без добавки).

При полусухом прессовании изделий вместе с водой в поры и капилляры заполнителя вносится цемент, из которого затем возникают кристаллические новообразования, связывающие зерна глиежа через тончайшие прослойки цементного камня, т.е. происходит «врастание» кристаллического сростка цементного камня в тело заполнителя. Это приводит к увеличению прочности как самого заполнителя, так и контакта с цементным камнем.

Минеральный состав горелых пород Бородинского месторождения исследовался методом PФА (рис. 2), идентификация минералов проводилась согласно американской картотеке ICDDPDF-2 Release 2008. Дифракционные максимумы соответствуют в основном кальциту (d=0,303; 0,249; 0,228; 0,210 нм и др.), а также алюмосиликатам группы полевых шпатов.

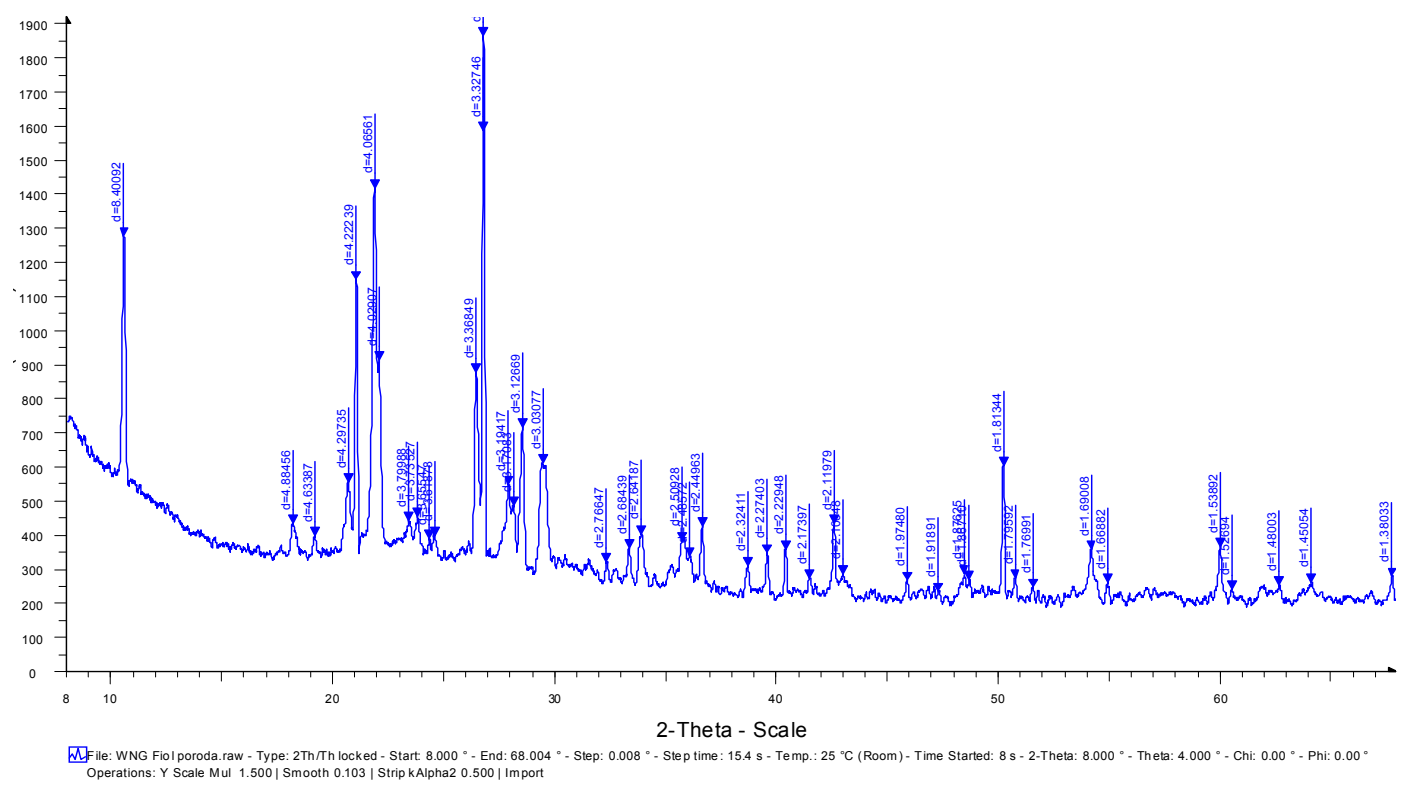

Рис. 2. Рентгенограмма усредненной горелой породы

$$
-569-
$$


Кальцит, присутствующий в глиежах, способен влиять на гидратацию С3А и C4AF. B результате взаимодействия с углекислыми слоями кальция цементной системы помимо кубического алюмината кальция (3СaO-A12O3·6H2O) образуется новое соединение - гидрокарбоалюминат кальция и/или магния. Количество гидроалюмината уменьшается, а гидрокарбоалюминаты срастаются между собой и с поверхностью карбонатных частиц зерен глиежа в плотный кристаллический конгломерат, что дополнительно стимулируется физическими процессами. Эти же процессы могут протекать в порах и в капиллярах частиц глиежа, куда всасывается вода, насыщенная продуктами гидролиза клинкерных минералов. Таким образом, сцепление с кальцитом осуществляется в результате взаимного структурного прорастания цементного камня и глиежа.

При технологии прессования большое значение приобретает механическая адгезия. Продукты гидролиза, проникая в поры, увеличивают в дальнейшем защемление, а молекулы адсорбируемого клеящего вещества (вяжущего) вступают в максимальное число контактов с молекулами поверхностей склеиваемых частиц, сокращая границу цементный камень - глиеж.

Изделия на основе горелых пород с прочностью при сжатии, соответствующей определенной марке по прочности керамического кирпича (ГОСТ 530-2012), имеют значительно более высокую прочность при изгибе, чем у керамического кирпича данной марки (табл. 5). Очевидно, усиленный контакт частиц глиежа с цементным камнем значительно улучшает сопротивление изгибающим усилиям так как отсутствие в прессованной композиции резко выраженной границы цементный камень - глиеж приводит к уменьшению неравномерности распределения деформаций между ними. Напряжения от внешних нагрузок накладываются на ультрамикроструктурные и микроструктурные неориентированные напряжения, всегда имеющиеся в бетонах, особенно тяжелых. В изделиях же на основе глиежа значения влажностных деформаций в заполнителе, разделенном тончайшими прослойками цементного камня, весьма уравновешены, поэтому микроструктурные напряжения в таких композициях невелики.

\section{Заключение}

Метод полусухого прессования дает возможность получить кирпич идеальной формы с минимальными отклонениями геометрических размеров, глянцевой поверхностью всех плоскостей, высокой прочности, с небольшим водопоглощением при пониженном расходе цемента. Кроме того, яркая, красивая окраска горелых пород дает возможность изготавливать из них лицевые стеновые изделия светло-розовых, желтых, бурых и красных тонов без введения красящих пигментов с обеспеченной морозостойкостью (ГОСТ 530-2012).

Таким образом, разработанные составы и технология могут быть рекомендованы для производства эффективных безобжиговых стеновых строительных материалов, отвечающих нуждам современного строительства.

\section{Список литературы}

[1] Книгина Г.И. Строительные материалы из горелых пород, М.: Стройиздат, 1986. 207 с. [Knigin GI Building materials made of burned rocks, M .: Stroyizdat, 1986. 207 p. (in Russian)]

[2] Canibano J.G. Latest developments in the utilization of coalmining wastes. Coal Science. Elsevie., Amsterdam. 1995, 1(2). 1629-1632. 
[3] Naik T.R. Use of industrial bv-products in cement-based materials. Creating and Concrete Research, 2004, 34 (11), 2057 - 2060.

[4] Scrivener K.L, Kirkpatrick R.J. Innovation in Use and Research on Cementitions Material. Proceedings of the 121 International Congress on the Chemistry of Cement. Montreal, 2007, 358278.

[5] Буравчук Н.И., Гурьянова О.В., Айрапетьян М.А. Использование пород шахтных отвалов для устройства земляного полотна. Известия вузов. Северо-Кавказский регион. Технические науки, 2007, 6, 100 - 104. [Buravchuk NI Guryanov OV Ayrapetyan MA Using rock mine dumps for the device subgrade. Proceedings of the universities. North-Caucasian region. Engineering 2007, 6, 100 - 104. (in Russian)]

[6] Буравчук Н.И. Ресурсосбережение в технологии строительных материалов. Ростов н/Д., 2009. 224 с. [Buravchuk NI Resource in building materials technology. Rostov n / D., 2009. 224 p. (in Russian)]

[7] Гамалий Е.Н. Горелые породы как активная минеральная добавка в бетон. Вестник ЮУрГУ, Строительство и архитектура, 2008,7(25), 22-27. [Gamaliy EN Burned rocks as an active mineral additive in concrete. Vestnik of SUSU, Construction and architecture, 2008.7 (25), 22-27. (in Russian)]

[8] Гипич Л.В. Особенности вещественного состава отвальных пород шахтных отвалов Восточного Донбасса и новые направления их использования: автореф. дис. ... канд.техн. 04.00.11. /Гапич Лариса Викторовна. - Ростов н/Д., 1998.- 25c. [Gipich LV Features of material composition of overburden Eastern Donbass mine dumps and the new direction of their use: Abstract. Dis. ... Kand.tehn. 04.00.11. / Gapich Larisa Viktorovna. - Rostov n / d, 1998.- 25c. (in Russian)]

[9] Коваленко Л.И., Омельченко Н.П. Перспективы использования горелых пород шахтных отвалов. Проблеміэкологіi. 2009, 1-2, 16-19. [Kovalenko LI Omelchenko, NP Prospects for the use of burned rocks mine dumps. Problemiekologii. 2009, 1-2, 16-19. (in Russian)]

[10] Майдукова С.С. Экономическая целесообразность использования ресурсного потенциала минеральной составляющей отходов угольного производства. Экономічнийвісник. 2013, 3, 145-153. [Maydukova SS The economic feasibility of the use of the resource potential of the mineral component of coal waste. Ekonomichniyvisnik. 2013, 3, 145 - 153. (in Russian) ]

[11] Мнухин А.Г. Породные отвалы - сырье будущего. Уголь Украины. 2009, 5, 28-32. [Mnukhin AG Dumps - the raw material of the future. Coal of Ukraine. 2009 5, 28-32. (in Russian)]

[12] Маилян Р.Л., Ахматов М.А. Железобетон на пористых каменных отходах. М.: Стройиздат, 1987. 208 с. [Mailyan RL Akhmetov MA Reinforced concrete on porous stone waste. M.: Stroyizdat, 1987. 208 p. (in Russian)] 